\title{
Closed Loop Controlled Low Noise SMPS System Using Forward Converter
}

\author{
P. Vijaya Kumar and Dr. S. Rama Reddy
}

\begin{abstract}
Simulation of DC-DC converter side in SMPS system is discussed in this paper. A forward type soft switching DC-DC converter topology with neutral point inductor connected Auxiliary resonant snubber (NPC-ARS) circuit is presented in this paper for the switching mode power supply applications. Its circuit operation and its performance characteristics of the forward type soft switching DC-DC converter is described and the simulation results are presented.
\end{abstract}

Index Terms-Forward type DC-DC converter, Zero voltage soft switching, Zero current soft switching, neutral point inductor connected Auxiliary resonant snubber (NPCARS) circuit

\section{INTRODUCTION}

In recent years, the switching mode power supply (SMPS) system have been achieved the high power density and high performances by developed power semiconductor devices such as IGBT, MOS-FET and SiC. However, using the switching power semiconductor in the SMPS system, the problem of the switching loss and EMI/RFI noises have been closed up. This course produced the EMC limitation like the International Special Committee on Radio Interference (CISPR) and the harmonics limitation like the International Electrotechnical Commission (IEC). For keeping up with the limitation, the SMPS system must add its system to the noise filter and the metal and magnetic component shield for the EMI/RFI noises and to the PFC converter circuit and the large input filter for the input harmonic current. On the other hand, the power semiconductor device technology development can achieve the high frequency switching operation in the SMPS system. The increase of the switching losses have been occurred by this high frequency switching operation. Of course, the inductor and transformer size have been reduced by the high frequency switching, while the size of cooling fan could be huge because of the increase of the switching losses.

Our research target is to reduce the EMI/RFI noises and the switching losses in the SMPS system by only one method. The solution method is the soft switching technique. Using LC resonant phenomenon, this technique can minimize the switching power losses of the power semiconductor devices, and reduce their electrical dynamic and peak stresses, voltage and current surge-related EMI/RFI noises under high frequency switching strategy.

Thus, a new conceptual circuit configuration of the advanced forward type soft switching DC-DC converter which has the neutral point inductor connected auxiliary

P. Vijaya Kumar, Research Scholar, Jawaharlal Nehru Technological University, Hyderabad, India.( dvvijayaharini@rediffmail.com)

Dr. S. Rama Reddy, Professor, Jerusalem College of Engineering, Chennai, India. (srr victory@yahoomail.com) resonant snubber (NPC-ARS) circuit is presented in this paper with its operating principle in steady state. In addition, its fundamental operation and its performance characteristics of the proposed forward type soft switching DC-DC converter treated here are evaluated on the basis of experimental results. A New Controller scheme for Photo voltaics power generation system is presented in [1]. The design and implementation of an adaptive tuning system based on desired phase margin for digitally controlled DC to DC Converters is given in [2]. Integration of frequency response measurement capabilities in digital controllers for DC to DC Converters is given in [3]. A New single stage, single phase, full bridge converter is presented in [4]. The Electronic ballast control IC with digital phase control and lamp current regulation is given in [5]. A New soft-switched PFC Boost rectifier/inverter is presented in [6]. Novel soft switched PWM current source rectifier is presented in [7]. The auxiliary resonant commutated pole converter is given by [8].Resonant snubbers with auxiliary switches is given in [9]. A control strategy for PWM current source rectifier is given in [10].Comparison of active clamp ZVT techniques applied to tapped inductor DC-DC converter is given in [11].The multiple output AC/DC Converter with an internal DC UPS is given in [12].The Bi-directional isolated DC-DC Converter for next generation power distribution comparison of converters using $\mathrm{Si}$ and Sic devices is given in [13]. The above literature does not deal with modelling and simulation of closed loop controlled SMPS System employing forward converter. This work aims to develop a model for the Closed loop SMPS System.

\section{NOvel Forward Type Soft Switching DC-DC CONVERTER}

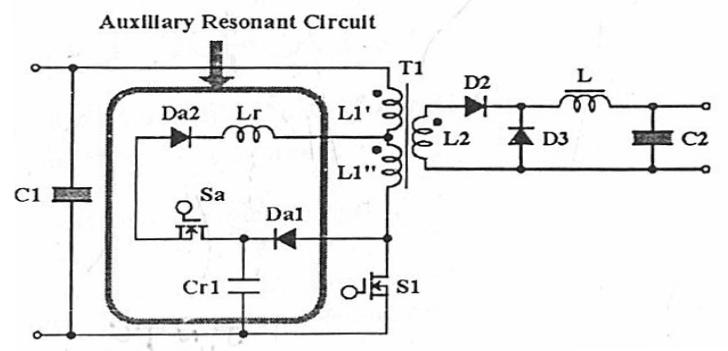

Fig.1.b Forward type soft switching DC-DC converter with a neutral point inductor connected auxiliary resonant snubber (NPC-ARS) circuit.

The typical switching mode power supply circuit configuration of our research target is shown in Fig.1.a. We have modified the part of DC-DC converter to achieve the complete soft switching operation in active power 
semiconductor devices of the forward converter. Fig.1.b shows the schematic configuration of the modified forward type soft switching DC-DC converter with a neutral point inductor connected auxiliary resonant snubber (NPC-ARS) circuit. The proposed NPC-ARS circuit consist of an active power semiconductor devices; $\mathrm{Sa}$, a resonant capacitor $\mathrm{Crl}$, two power diode Da1 and Da2. Using this NPC-ARS circuit, the zero voltage soft switching (ZVS) turn off or the zero current soft switching (ZCS) turn on can be achieved in main switching device S1 and ZCS turn on and turn off be in auxiliary switch Sa. So that, the switching losses in each active power semiconductor device will be zero completely.

\section{OPERATION PRINCIPLE OF NPC-ARS CIRCUIT}

The operation principle of the proposed forward type soft switching DC-DC converter with the NPC-ARS circuit is illustrated in Fig.1.c. The conventional forward type DCDC converter operates only two circuit condition mode which is described in Fig.1.c as the steady state mode on and off. On the other hand, there is 4 mode in case of the proposed one as depicted in Fig.1.c. The operating principle of the proposed forward type soft switching DC-DC converter is described as follows;

Steady State Mode one : In this state, the transformer current flows through the main active power semiconductor device S1 and the primary energy conducts to secondary side of transformer. If the main active power semiconductor device $\mathrm{S} 1$ is turned off, the operation mode changes to the next circuit condition mode, Commutation Mode 1.

[Commutation Mode 1]; The energy in the leakage inductance of transformer $\mathrm{T} 1$ is flowing through the resonant capacitor $\mathrm{Crl}$ by turned main active power semiconductor devices S1 off. When the leakage inductance current reach zero, the operation mode changes to the next steady state mode, Steady State Mode OFF.

[Steady State Mode OFF]; The energy in the primary side of transformer is broken off the secondary side in this circuit condition mode. If the main active power semiconductor device $\mathrm{S} 1$ and auxiliary active power semiconductor device $\mathrm{Sa}$ are turned on the operation mode changes to the next circuit condition mode, Commutation Mode 2.

Commutation Mode 2: In this mode, the active power semiconductor devices $\mathrm{S} 1$ and $\mathrm{Sa}$ can be achieved the complete ZCS transition by the leakage inductance and auxiliary resonant inductor Lr. The energy in the primary side of transformer $\mathrm{T} 1$ is conducted to the secondary side. Furthermore, the energy in the resonant capacitor Crl flow to the secondary side of the transformer through the transformer T1. When the voltage of the resonant capacitor $\mathrm{Crl}$ reaches zero, the operation mode is changed to the first circuit condition mode, Steady State Mode ON.

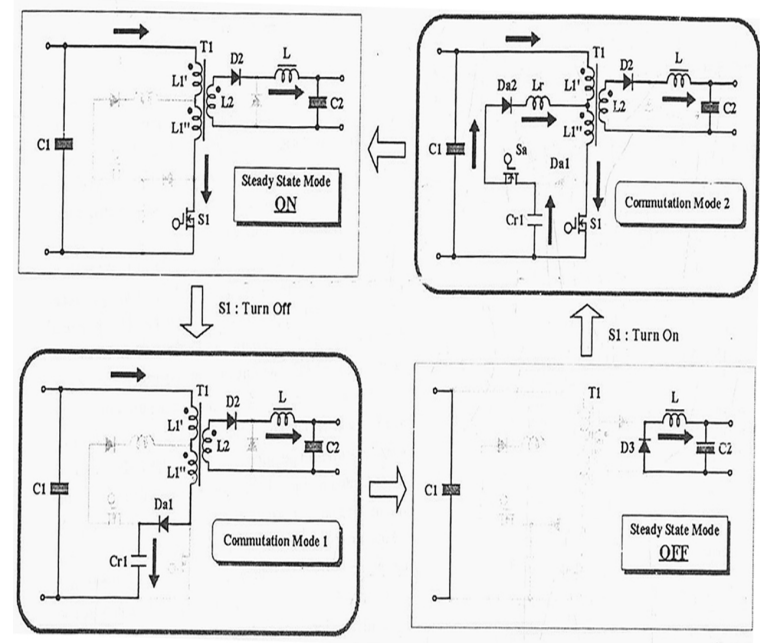

Fig.1.c. Equivalent circuit for each operation stage of the proposed forward type soft switching DC-DC converter with the NPC-ARS circuit

\section{Simulation Results}

The SMPS system is modelled and simulated using the blocks of MATLAB SIMULINK.The SMPS system using conventional boost and forward converters is shown in Fig.2.a. Diode rectifier with capacitor filter was represented as a D.C source at the input. The current and voltage waveforms of $\mathrm{S} 2$ are shown in Fig.2.b. The voltage across the primary of the transformer is shown in Fig.2.c. The voltage across the secondary of the transformer is Fig.2.d, the voltage across the diode $\mathrm{d} 3$ is shown in Fig.2.e.From the waveforms it can be seen that the output contains noise.

Modified SMPS system using auxiliary switch in the forward converter is shown in Fig.3.a. The voltage and current waveform of S2 are shown in Fig.3.b. Voltage across the primary of the transformer is shown in Fig.3.c. The voltage across the secondary of the transformer is shown in Fig.3.d. The voltage across the diode D3 is shown in Fig.3.e. From the above waveforms it can be seen that the output is free from noise.

Open loop controlled SMPS system with a disturbance at the input is shown in Fig.4.a. A step change in input voltage is shown in Fig.4.b. The driving pulses for S2 and S3 are shown in Fig.4.c. Output voltage with disturbance is shown in Fig.4.d. It can be seen there is an increase in the output when there is an increase in the input. Closed loop controlled modified SMPS system is shown in Fig.5.a. Output voltage is sensed and it is compared with a reference value. The error is processed using PI controller. The output of the PI controller drives the MOSFET in the boost converter to regulate the output voltage. The driving pulses of $\mathrm{S} 1$ are shown in Fig.5.b. D.C output voltage is shown in Fig.5.c. The output voltage reduces to the set value. Thus the closed loop system is able to maintain constant voltage at the output. 


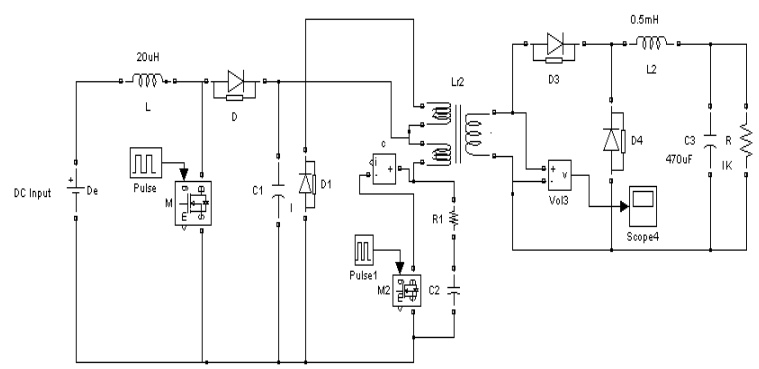

Fig.2.a. Conventional Boost \& forward converter

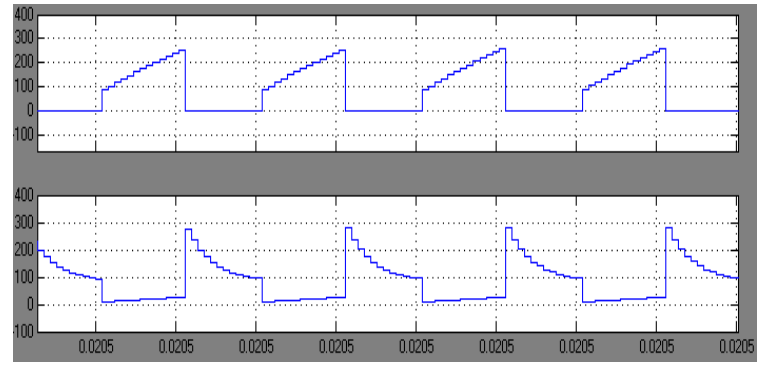

Fig.2.b. Current and voltage waveforms of S2

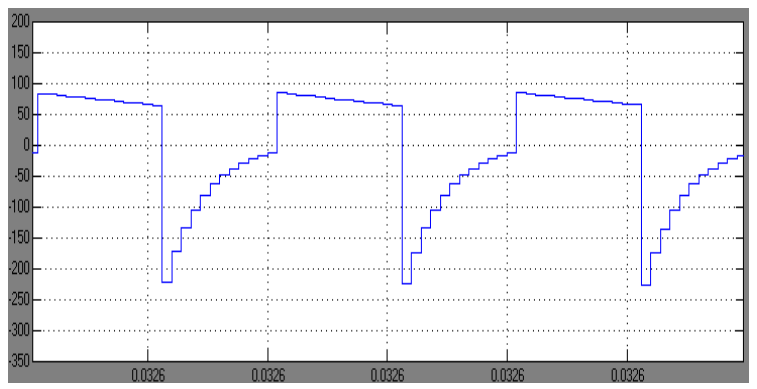

Fig. 2.c. Transformer primary voltage

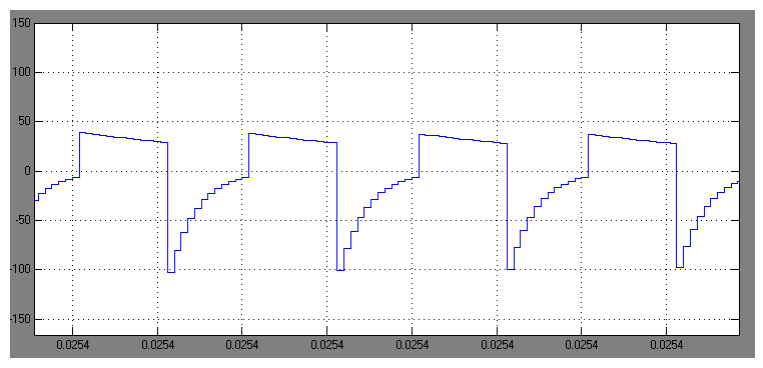

Fig.2.d. Transformer secondary voltage

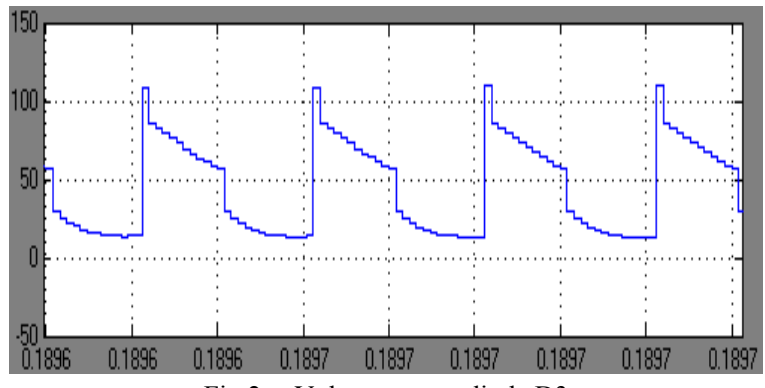

Fig.2.e. Voltage across diode D3

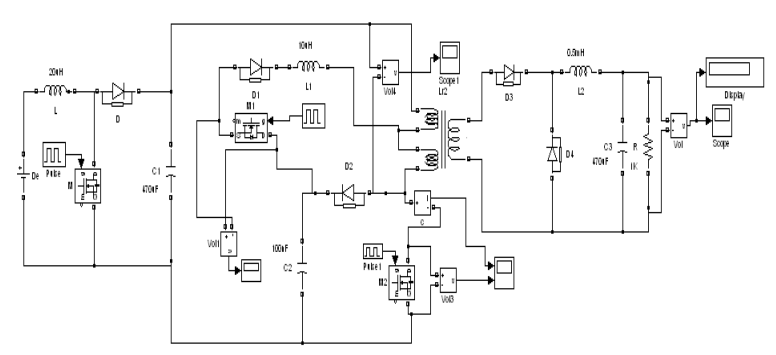

Fig.3.a. Modified SMPS system using auxiliary switch in the forward converter

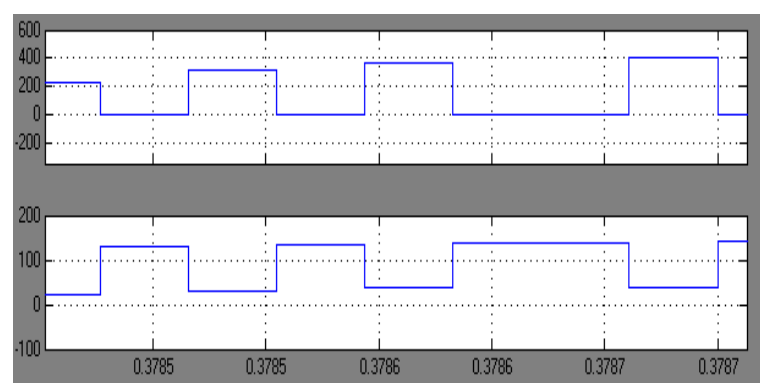

Fig.3.b. Current and voltage waveforms of S2

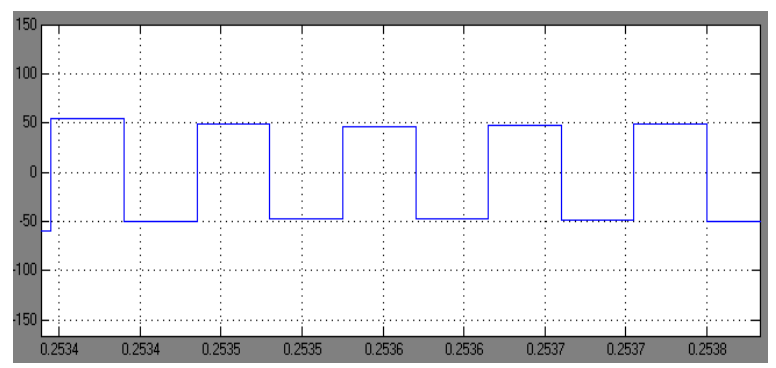

Fig.3.c.Transformer primary voltage

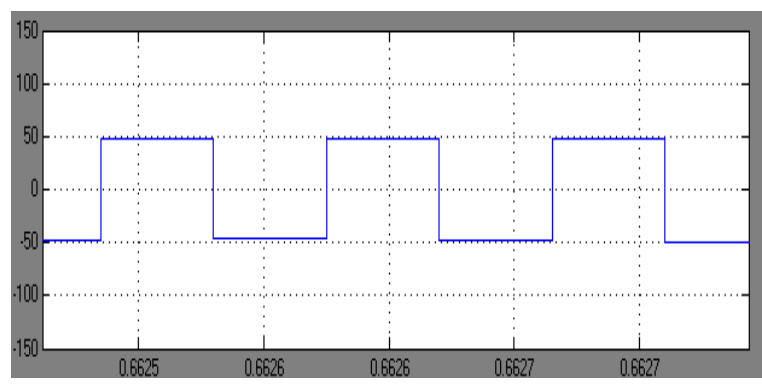

Fig.3.d. Transformer secondary voltage

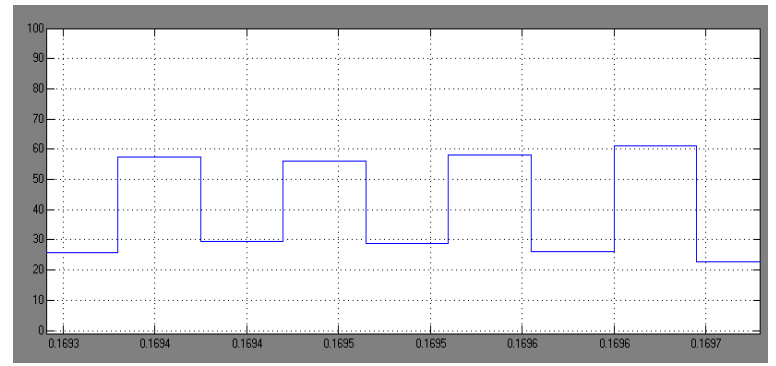

Fig.3.e. Voltage across diode D3 


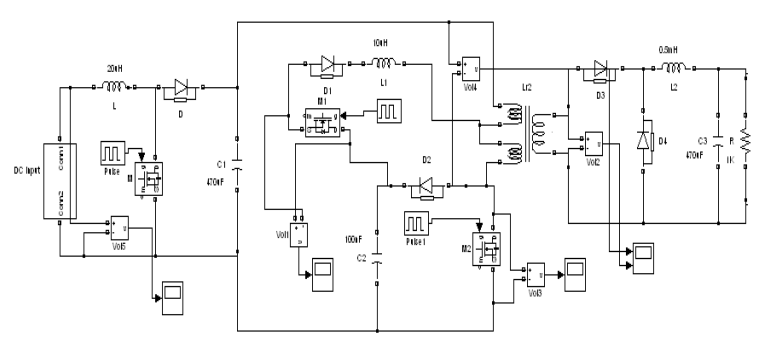

Fig.4.a. Open loop controlled SMPS system with a disturbance at the input

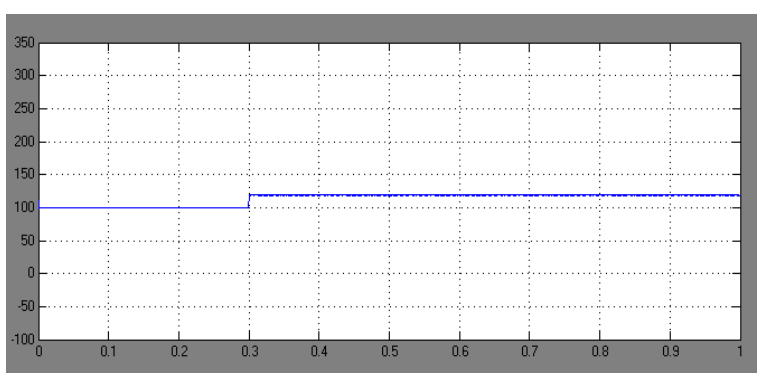

Fig.4.b. Input DC voltage with disturbance

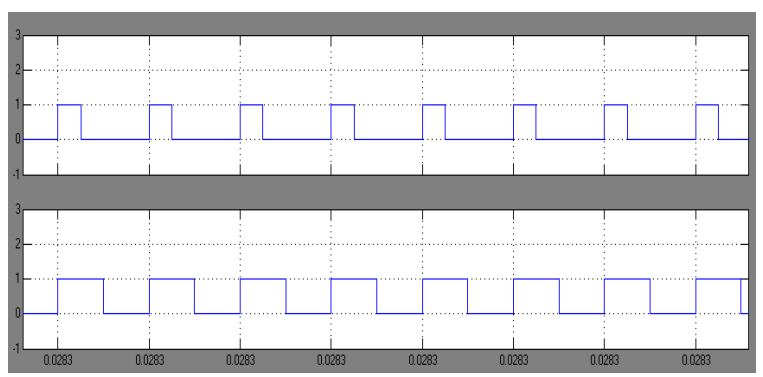

Fig.4.c. Driving pulses for S2 \& S3

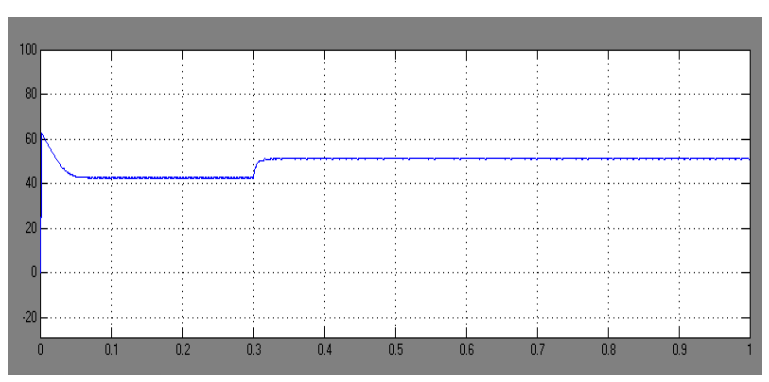

Fig.4.d. Output DC voltage with disturbance

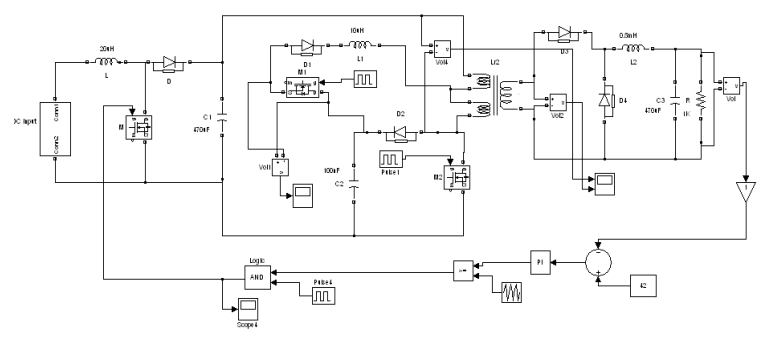

Fig.5.a. Closed loop controlled modified SMPS system

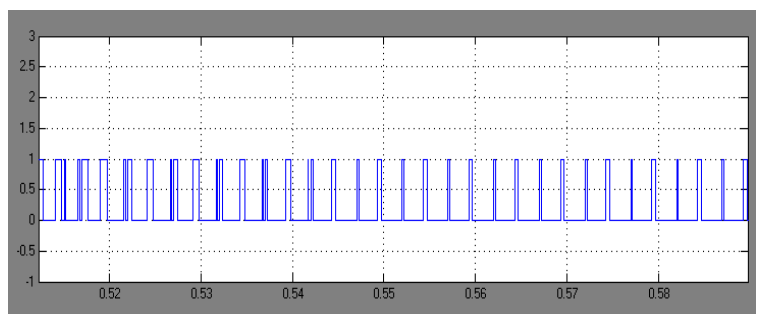

Fig.5.b. Driving pulses of S1

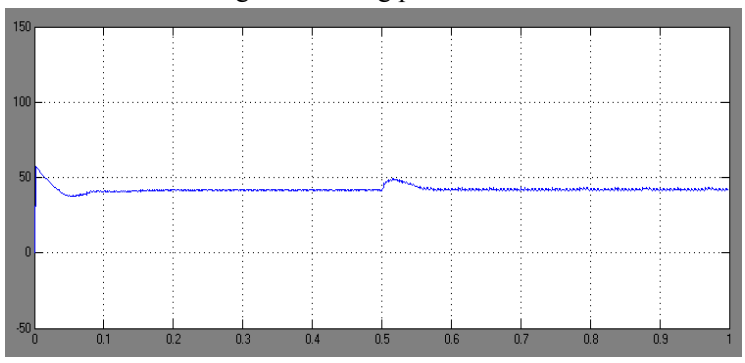

Fig.5.c.DC output voltage

\section{CONCLUSION}

Modified circuit configuration of forward type D.C D.C converter with its working principle is presented in this paper. The conventional and modified SMPS system are digitally simulated using Sim power systems. From the simulation results it is conformed that the modified converter has reduced noise in the output. Closed loop circuit model is developed and it is used for performing the simulation of closed loop system. From the simulation results it is observed that the steady state error in the output is reduced using closed loop system.

\section{REFERENCES}

[1] Tamer T.N.Khabib, Azah Mohamed, Nowshad Admin,"A New Controller Scheme for Photo voltaics power generation system,"European journal of scientific research ISSN 1450-216X vol.33 No.3 (2009), pp.515-524.

[2] J.Morroni, R.Zane, D.Maksimovic, "Design and Implementation of an adaptive tuning system based on desired phase margin for digitally controlled DC-DC Converters, "IEEE Trans. Power Electron.,vol.24,no.2,pp.559-564,feb.2009.

[3] M.Shirazi,J.Morroni,A.Dolgov,R.Zane,D.Maksimovic,'Integration of frequency response measurement capabilities in digital controllers for DC-DC Converters,"IEEETrans.Power Electron.,vol.23, no.5,pp.2524-2535,sep.2008.

[4] Hugo Ribeiro, Beatriz V.Borges,"New single stage, single phase, full Bridge Converter, "submitted for appreciation to the Technical committee of IEEE ECCE-Energy conversion congress and exhibition, January 2009.

[5] Y.Yin, M.Shirazi, R.Zane,'Electronic Ballast control IC with digital phase control and lamp current regulation,"IEEETrans.Power Electron., vol.23, no.1, pp.11-18, jan.2008.

[6] Yungtaek Jang,David L.Dillman and Milan M.Javanovie,"A New soft-switched PFC Boost Rectifier with Integrated Flyback Converter for stand -by Power,'IEEE Trans.on Power Electronics,pp.6672,No.1,2006.

[7] Gerry Moschopoulos and Geza Joos, "A Novel Soft-Switched PWM Current Source Rectifier/ Inverter", Proc. of 25th IEEE Annual Power Electronics Specialists Conference, pp.978-984, 1994.

[8] R.W. De Doncker "The Auxiliary Resonant Commutated Pole Converter", IEEE IAS '89 Records, pp.829-834, 1989.

[9] W.MacMarray "Resonant Snubbers with Auxiliary Switches", IEEEIAS7'89 Records, pp.829-834, 1989.

[10] Braz J. Cardoso Filho, Steffen Bernet and Thomas A. Lipo, "A New Control Strategy for the PWM Current Stiff Rectifier/Inverter with Resonant Snubber", Proc. of 28th IEEE Annual Power Electronics Specialists Conference, pp.574-579, June, 1997.

[11] S. Abe, T. Ninomiya, Comparison of Active-Clamp and ZVT Techniques Applied to Tapped-Inductor DC-DC Converter with Low Voltage and High Current, Journal of Power Electronics, Vol.2, No.3, pp.199-205, 2002.

[12] Arturo Fernandez,Member,IEEE,Javier sebastin,Member IEEE,Maria Hernando Member IEEE,'Multiple output AC/DC Converter with an Internal DC UPS,"IEEE Trans on Industrial Electronics.vol.53.no.1.Feb.2006.

[13] Aggeler,D-;Inove,S-;Akagi,H-;Kolar,J.W,'Bi-directional isolated DC to DC Converter for next generation power distribution-comparison of converters using $\mathrm{Si}$ and $\mathrm{Sic}$ devices "Power conversion conference-Nagoya.2007.PCC apos; 07,volume,Issue,2-5 April 2007 Page(s):510-517. 


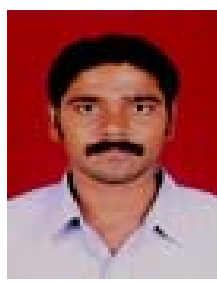

P.Vijayakumar received his B.E degree in Electronics and Communication Engineering from V.R.S College of Engineering and technology, Madras University, Chennai, India in 2002 and M.Tech degree in Power Electronics and Drives from Bharath Institute of Higher Education and Research, Bharath University, Chennai, India in 2005.Currently he is Pursuing Ph.D degree in Jawaharlal Nehru Technological University, Hyderabad, India. He has 6 years of teaching experience and 3 years of Industrial experience and he is a member of IEEE. His research area is on SMPS System.

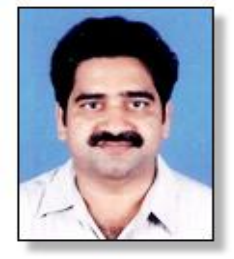

Dr.S.RamaReddy received his M.E degree from College of Engineering, Anna University, Chennai, India in 1987.He received Ph.D degree in the area of Resonant Converters from College of Engineering, Anna University, Chennai, India in 1995.Presently he is working as Dean in Electrical and Electronics Department, Jerusalem College of Engineering, Chennai. He has worked in Tata Consulting Engineers and Anna University, Chennai, India. He is fellow member of Institution of Electronics and Telecommunication Engineers (India), Life Member of Institution of Engineers (India), Member of ISTE, Member of CSI and Member of SPE, India. He has authored text books on Power Electronics, Electronic Circuits and Electromagnetic Fields. He has Published 30 research papers in reputed journals. His research areas are Power Electronic Converters, Drives and FACTS.

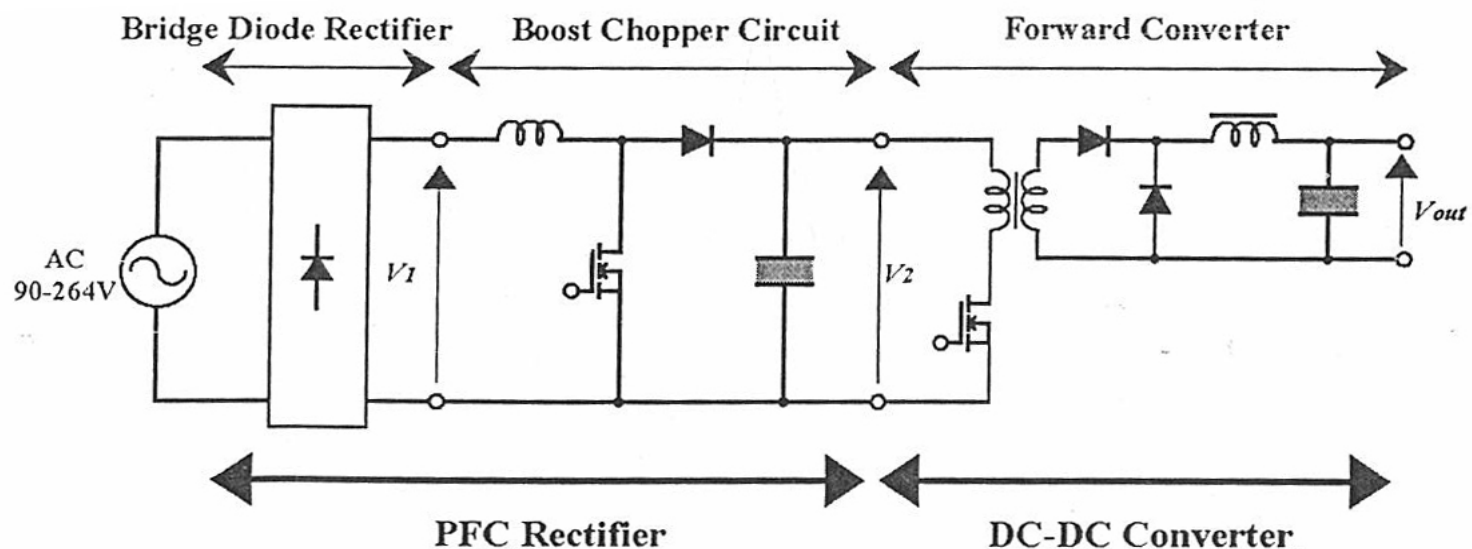

Fig.1.a. SMPS configuration of research target 